\title{
Grand Challenges in Earth Observation Using Unpiloted Airborne Systems
}

\author{
Steven M. de Jong * \\ Faculty of Geosciences, Utrecht University, Utrecht, Netherlands
}

Keywords: environmental applications, ecology, vegetation, geomorphology, hazards, protocols and standards, machine learning

Society will face enormous problems for the forthcoming decades to preserve a safe and healthy living environment (Nelson et al., 2013; Watson et al., 2020) and to assure sufficient fresh water for all (Wada et al., 2014; Bierkens and Wada, 2019). The impact of human activities on the climate system is well established, and unsustainable emissions of greenhouse gasses will continue to be high for the coming decades (IPCC, 2014). Even under optimistic scenarios, such as limiting warming by the end of the century to 1.5 or $2.0^{\circ} \mathrm{C}$ above pre-industrial conditions, climate change impacts will be considerable (Kraaijenbrink et al., 2017; IPCC, 2018). The warming up of the Earth and shifting patterns of precipitation and drought have significant impact on natural systems, our agricultural activities, natural resources, ecology, and the living environment. Some regions are more prone to global change than others and we must assess that vulnerability to be prepared and to mitigate the negative effects. Next to the threat of climate change there are health threats like the COVID-19 event that greatly reduced economic activities and mobility worldwide (Silver, 2020). Similar ecological events are likely to occur over the next decade due to the high world population numbers, the great mobility of people, the visits into remote unexplored areas and climate change (Boldog et al., 2020; Ivanov, 2020).

Monitoring our environment using a wide range of remote sensing systems, building up knowledge about the functioning of "System Earth" and developing models and methods for safeguarding our living environment becomes increasingly important. Much of what we know about "System Earth" and about changes at the Earth surface is derived from information acquired by remote sensing systems. A wide suite of spaceborne sensors in the optical, thermal, and microwave spectrum, systems measuring gravity fields and atmospheric composition provide that essential information (Belward and Skøien, 2015; Denis et al., 2017). Manned airborne observations are rare and often experimental and do not contribute to long-term standardized monitoring of the Earth surface (Tan, 2016). While low spatial resolution Earth observation using sensors, such as Moderate Resolution Imaging Spectroradiometer and Advanced Very High Resolution Radiometer of the National Oceanic and Atmospheric Administration, are suitable for global studies of changes at the Earth surface, historic archives of moderate resolution images such as National Aeronautics and Space Administration-Landsat (since 1984) and European Space AgencySentinel (since 2015) with optical and microwave images are well suited for regional studies, and archives of high-resolution images of, e.g., OrbView, Ikonos, Pleiades, PlanetLabs are available for local studies (Zhu \& Scott Mackay, 2001; Gorelick et al., 2017; Zhu, 2017). Some of these datasets are freely available, others are commercial datasets. Examples of successful studies of mapping Earth surface change are in the field of deforestation (Kennedy et al., 2012; Kennedy et al., 2018), landslides (Deijns et al., 2020), land cover (Kaptué Tchuenté et al., 2011; Wulder et al., 2018; Zurqani et al., 2018), glaciers and ice sheets (Rignot and Thomas, 2002; Anderson, 2011; Mouginot et al., 2017; Zhang et al., 2018; Zhang et al., 2020).

Over recent decades, Unpiloted Airborne Systems (UASs) have developed in a very fast and extraordinary way and filled the scale gap between spaceborne observations and detailed field, often point observations. The UASs are adding an sizable amount of local and regional spatio-temporal knowledge about surface processes and land cover dynamics (González-Jorge et al., 2017; Liew et al., 
2017; Tatum \& Liu, 2017; Tmušić et al., 2020). The UASs acquired images are typically applied as valuable information at a spatial scale in between spaceborne imagery and field observations, and to study regions with high surface dynamics or to collect images of inaccessible areas. The use of UASs acquired data for environmental research has grown enormously over the last decade as has the number of published papers and special issues on UASs technology and applications (Colomina and Molina, 2014; González-Jorge et al., 2017; Liew et al., 2017; Sigala and Langhals, 2020). Various types and categories of UASs systems are available such as fixed-wing, rotary type, flapping-wing, and balloon (González-Jorge et al., 2017; Liew et al., 2017). UASs have important advantages over other types of remote sensing. UASs are small and easy to transport, images are not affected by clouds, they are easy to deploy, they can carry various types of payloads and sensors, they deliver ultra-high-resolution imagery at centimetre resolution. UASs can normally fly on demand while spaceborne and airborne image acquisitions require thorough planning and might be hampered by unfavourable weather conditions or other campaigns with higher priorities.

UASs have an increasing endurance and increasing payload capacity, overflights can easily be repeated at a frequency desired and the requirements for a skilled pilot are diminished because of the development of auto-flight modes and autonomous flying. UASs had to be manually controlled by human operators until 10 years ago but developments have rapidly progressed toward various degrees of autonomous flying using pre-designed or standard flight plans. Even small drones are now often equipped with a Differential Global Position System and some have Inertial Measurement Units facilitating the geocoding of the images and of the flight tracks.

Advances in technology and availability have boosted the number of applications in many sectors but especially in regions with local and regional dynamic features. Just a few innovative and successful examples of UAS-based monitoring are glacier monitoring for ice flow and mass wasting (Immerzeel et al., 2014; Kraaijenbrink et al., 2016), landslide dynamics monitoring and surface deformation (McKean, 2004; Niethammer et al., 2012; Lucieer et al., 2014; Giordan et al., 2020; Karantanellis et al., 2020), dune dynamics (Ruessink et al., 2018), flood risk mapping (Hashemi-Beni et al., 2018), night-timelight monitoring as proxy for economic activity (Li et al., 2020), public health care and health-related services (Amukele et al., 2015; Scalea, 2020), and post-disaster damage assessment (Kerle et al., 2019; Liao et al., 2020).

Several important challenges for the successful and responsible scientific use of UASs are listed below. The list is by no means comprehensive and not meant to exclude other topics, it serves as a discussion on the ways ahead regarding the technical developments of UASs and the applied use of UAS collected data.

Payloads. Most conventional payloads on UASs are RGB (Red, Green, Blue) cameras. Over recent years many other types of sensors were mounted such as color infrared cameras, thermal cameras (Messina \& Modica, 2020), Light Detection and Ranging systems (Wallace et al., 2014; Wallace et al., 2016) and even imaging spectrometers (Aasen et al., 2018). Non-imaging sensors such as temperature sensors, air pressure or gas sensors (Pering et al., 2020) are also used on UAS platforms. Multi- sensors as payload on UASs are currently developed and evaluated for use. As technology advances, more and more sensors types aboard UASs will become available giving challenges for power supply, stability, and data processing.

Environmental applications. For many years, UASs have been widely used in scientific studies and for standard surveying. Emphasis is still put on a limited number of applications such as those mentioned above and for precision agriculture, crop biomass development, food and water security, vegetation mapping (forest, grassland, wetlands, riparian), coastal systems, topographic survey, geomorphology, archaeology, health-related services, snow and ice dynamics, and landslide monitoring. There are, however, a huge range of applications that remain under explored. A focus for the new Frontiers in Remote Sensing journal will be to be as inclusive as possible and promote the use of UASs in a wide variety of environmental fields.

Generation of high accuracy elevation models. Key products of UAS-acquired images and Light Detection and Ranging sets are digital elevation models (DEMs) and DEM-derived products. Such products are valuable for flood-risk assessment (HashemiBeni et al., 2018), surface deformation studies and landslide monitoring (Lucieer et al., 2014; Turner et al., 2015), glacierand ice sheet dynamics (Immerzeel et al., 2014; Kraaijenbrink, 2018). It is a challenge to generate high quality DEMs, to optimise algorithms such as "structure from motion" (Smith et al., 2015; James et al., 2019) and to assess the quality of these products. Papers addressing these topics and applications of DEMs and DEM-products are invited.

Image acquisition and processing protocols and standards. There are hardly any standard protocols for planning UAS surveys, for the proper use of ground control points and Global Navigation Satellite System, for platform and camera/sensor choice, for processing of UAS-acquired data (georeferencing, DEM generation (James et al., 2019), radiometric, and atmospheric corrections) and for image information extraction, sensor calibration and error characterization and accuracy assessment (Singh and Frazier, 2018; Tmušić et al., 2020). It is a challenge and a requirement for the development of successful UAS data application to define and build such protocols.

Autonomous flying. The use of UASs has developed from fully manual operator-controlled flying to auto-pilot flights. Developments are rapidly proceeding toward fully autonomous operating and flying UASs automatically carrying out their data and image collection and uploading the data to a server. This comes with technical and legal challenges that need to be solved (Sigala and Langhals, 2020). So far, autonomous flying is being tested for a limited number of applications, such as precision agriculture. Other interesting developments are toward self-calibration during the flight giving various aerodynamic and topographic conditions (Laupré \& Skaloud, 2020) which will be beneficiary for platform stability and flight accuracy. Next, autonomous mobile ground control point systems are becoming available to optimise UAS data collection and improve georeferencing (Han et al., 2020). Fully automated operating UASs for a range of applications are soon available and will become rapidly operational.

UAS data analysis using machine learning. Machine learning and advanced "Big Data" analysis methods have developed 
considerably over recent years. Methods such as Random Forests, Support Vector Machines, Convolution Neural Networks will contribute largely to the high-speed and possible automated analysis of the huge amount of drone data that can be collected during just a few field surveys (Khan and Al-Mulla, 2019; Liao et al., 2020).

Quality assurance of products. The production of high quality UAS-products starts, as stated above, by well-followed image acquisition protocols in the field, a well organised flight plan and mission, good georeferencing using Differential Global Position System or Ground Control/Reference Points and an image geometry model. Where necessary, radiometric calibration must be applied by, for example, sensor calibration or atmospheric transmission models. The next processing step is to convert the data/images into high quality products such as image mosaics, DEMs, quantitative biomass maps, classified land cover maps etc. Reliable reference data collected in the field is often necessary to assess the quality of the products (Tmušic et al., 2020). A well-described proposal for data quality procedures and protocols is given by Tmušić et al. (2020) but needs to be further developed. This will be another challenge for the UAS user community.

Legislation and regulation. UASs come in many forms ranging from small toys to military drones. They have great potential for scientific applications, however the unbridled growth of UASs both commercially and scientifically pose a challenge for legislation and regulation (Jackman, 2020). While in the early days of UASs there were hardly any rules, that has changed rapidly over the last decade. Flights are now often restricted to specific maximum flight height, depending on the type of operation, size, and weight of the aircraft, and pilot and company licensing (Tmušić et al., 2020), and

\section{REFERENCES}

Aasen, H., Honkavaara, E., Lucieer, A., and Zarco-Tejada, P. J. (2018). Quantitative remote sensing at ultra-high resolution with UAV spectroscopy: a review of sensor technology, measurement procedures, and data correctionworkflows. Remote Sens. 10 (7), 1-42. doi:10.3390/rs10071091

Amukele, T. K., Sokoll, L. J., Pepper, D., and Howard, D. P. (2015). Can unmanned aerial systems (drones) Be Used for the routine Transport of chemistry, hematology, and coagulation laboratory Specimens? PLoS One 10 (7), e0134020. doi:10.1371/journal.pone.0134020

Belward, A. S., and Skøien, J. O. (2015). Who launched what, when and why; trends in global land-cover observation capacity from civilian earth observation satellites. ISPRS J. Photogramm. Remote Sens. 103, 115-128. doi:10.1016/j. isprsiprs.2014.03.009

Bierkens, M. F. P., and Wada, Y. (2019). Non-renewable groundwater use and groundwater depletion: a review. Environ. Res. Lett. 14 (6), 1-43. doi:10.1088/ 1748-9326/abla5f

Boldog, P., Tekeli, T., Vizi, Z., Dénes, A., Bartha, F. A., and Röst, G. (2020). Risk assessment of Novel Coronavirus COVID-19 outbreaks outside China. J. Clin. Med. 9 (2), 571. doi:10.3390/jcm9020571

Colomina, I., and Molina, P. (2014). Unmanned aerial systems for photogrammetry and remote sensing: a review. ISPRS J. Photogramm. Remote Sens. 92, 79-97. doi:10.1016/j.isprsprs.2014.02.013

Deijns, A. A. J., Bevington, A. R., van Zadelhoff, F., de Jong, S. M., Geertsema, M., and McDougall, S. (2020). Semi-automated detection of landslide timing using harmonic modelling of satellite imagery, Buckinghorse River, Canada. Int. J. Appl. Earth Obs. Geoinf. 84, 101943. doi:10.1016/j. jag.2019.101943 prohibited in some locations. The European Commission is striving toward harmonizing the rules which is an important step in the right direction (European Commission, 2019). Workable regulations for all UAS users will be another challenge for the UAS community.

The aim of the Unpiloted Aerial Systems (UASs and UAVs) specialty section within Frontiers in Remote Sensing is to provide a platform for publishing scientific papers on new developments of UAS technology, on a wide variety of environmental applications, on image and data acquisition procedures, on methods and algorithms for pre-processing and on information extraction approaches from UAS datasets, on data and image quality control standards and procedures. Occasionally, papers on regulations and legislation will be published. These published scientific papers with methods, techniques, standards, applications, and protocols will yield a solid scientific and practical basis to monitor and understand our living environment, which helps to preserve and manage our resources.

\section{AUTHOR CONTRIBUTION}

The author confirms being the sole contributor of this work and has approved it for publication.

\section{ACKNOWLEDGMENTS}

W. W. Immerzeel and P. D. A. Kraaijenbrink are acknowledged for their valuable remarks and suggestions.

Denis, G., Claverie, A., Pasco, X., Darnis, J. P., de Maupeou, B., Lafaye, M., et al. (2017). Towards disruptions in Earth observation? New Earth Observation systems and markets evolution: possible scenarios and impacts. Acta Astronaut. 137, 415-433. doi:10.1016/j.actaastro.2017.04.034

European Commission (2019). Commission Delegated Regulation (EU) 2019/945 of 12 March 2019 on unmanned aircraft systems and on third-country operators of unmanned aircraft systems. 2019, C/2019/1821. Available at: http://data.europa.eu/eli/reg_del/2019/945/oj.

Giordan, D., Adams, M. S., Aicardi, I., Alicandro, M., Allasia, P., Baldo, M., et al. (2020). The use of unmanned aerial vehicles (UAVs) for engineering geology applications. Bull. Eng. Geol. Environ. 79, 3437-3481. doi:10.1007/s10064-02001766-2

González-Jorge, H., Martínez-Sánchez, J., Bueno, M., Arias, A. P., and Arias, P. (2017). Unmanned aerial systems for civil applications: a review. Drones 1 (1), 2. doi:10.3390/drones1010002

Gorelick, N., Hancher, M., Dixon, M., Ilyushchenko, S., Thau, D., and Moore, R. (2017). Google earth engine: planetary-scale geospatial analysis for everyone. Remote Sens. Environ. 202 (2016), 18-27. doi:10.1016/j.rse.2017.06.031

Han, X., Thomasson, J.A., Wang, T., and Swaminathan, V.(2020). Autonomous mobile ground control point improves accuracy of agricultural remote sensing through collaboration with UAV. Inventions 5 (1), 12. doi:10.3390/inventions5010012

Hashemi-Beni, L., Jones, J., Thompson, G., Johnson, C., and Gebrehiwot, A. (2018). Challenges and opportunities for UAV-based digital elevation model generation for flood-risk management: a case of Princeville, North Carolina. Sensors 18 (11), 3843. doi:10.3390/s18113843

Immerzeel, W. W., Kraaijenbrink, P. D. A., Shea, J. M., Shrestha, A. B., Pellicciotti, F., Bierkens, M. F. P., et al. (2014). High-resolution monitoring of Himalayan glacier dynamics using unmanned aerial vehicles. Remote Sens. Environ. 150, 93-103. doi:10.1016/j.rse.2014.04.025 
IPCC (2014). “Climate change 2014,"in In climate change 2014: synthesis report. Editors R. K. Pachauri and L.A. Meyer (Geneva, Switzerland: IPCC). doi:10. 1017/CBO9781107415324

IPCC (2018). Global warming of $1.5^{\circ} \mathrm{C}$. An IPCC special report on the impacts of global warming of $1.5^{\circ} \mathrm{C}$ above pre-industrial levels and related global greenhouse gas emission pathways, in the context of strengthening the global response to the threat of climate change. Available at: https://www.ipcc.ch/site/assets/ uploads/sites/2/2019/06/SR15_Full_Report_Low_Res.pdf.

Ivanov, D. (2020). Predicting the impacts of epidemic outbreaks on global supply chains: a simulation-based analysis on the coronavirus outbreak (COVID-19/ SARS-CoV-2) case. Transp. Res. Part E: Logist. Transp. Rev. 136, 101922. 136, 101922. doi:10.1016/j.tre.2020.101922

Jackman, A. (2020). Digital warfighting temporalities and drone discourse. Digital War. 1, 1-13. doi:10.1057/s42984-020-00003-0

James, M. R., Chandler, J. H., Eltner, A., Fraser, C., Miller, P. E., Mills, J. P., et al. (2019). Guidelines on the use of structure-from-motion photogrammetry in geomorphic research. Earth Surf. Process. Landf. 44 (10), 2081-2084. doi:10. 1002/esp. 4637

Kaptué Tchuenté, A. T., De Jong, S. M., Roujean, J.-L., Favier, C., and Mering, C. (2011). Ecosystem mapping at the African continent scale using a hybrid clustering approach based on 1-km resolution multi-annual data from SPOT/ VEGETATION. Remote Sens. Environ. 115 (2), 452-464. doi:10.1016/j.rse. 2010.09.015

Karantanellis, E., Marinos, V., Vassilakis, E., and Christaras, B. (2020). Objectbased analysis using unmanned aerial vehicles (UAVs) for site-specific landslide assessment. Remote Sens. 12 (11), 1711. doi:10.3390/rs12111711

Kennedy, R. E., Yang, Z., Cohen, W. B., Pfaff, E., Braaten, J., and Nelson, P. (2012). Spatial and temporal patterns of forest disturbance and regrowth within the area of the Northwest Forest Plan. Remote Sens. Environ. 122, 117-133. doi:10. 1016/j.rse.2011.09.024

Kennedy, R. E., Yang, Z., Gorelick, N., Braaten, J., Cavalcante, L., Cohen, W. B., et al. (2018). Implementation of the LandTrendr algorithm on Google earth engine. Remote Sens. 10 (5), 1-10. doi:10.3390/rs10050691

Kerle, N., Nex, F., Gerke, M., Duarte, D., and Vetrivel, A. (2019). UAV-based structural damage mapping: a review. ISPRS Int. J. Geo-Inf. 9 (1), 1-23. doi:10. 3390/ijgi9010014

Khan, A. I., and Al-Mulla, Y. (2019). Unmanned aerial vehicle in the machine learning environment. Procedia Comput. Sci. 160, 46-53. doi:10.1016/j.procs. 2019.09.442

Kraaijenbrink, P. D. A., Bierkens, M. F. P., Lutz, A. F., and Immerzeel, W. W. (2017). Impact of a global temperature rise of 1.5 degrees celsius on Asia's glaciers. Nature 549 (7671), 257-260. doi:10.1038/nature23878

Kraaijenbrink, P. D. A. (2018). High-resolution insights into the dynamics of Himalayan debris-covered glaciers. Utrecht Studies in Earth Sciences 159, PhD dissertation, Utrecht, Netherlands. Utrecht University, 250pp.

Kraaijenbrink, P. D. A., Shea, J. M., Pellicciotti, F., Jong, S. M. d., and Immerzeel, W. W. (2016). Object-based analysis of unmanned aerial vehicle imagery to map and characterise surface features on a debris-covered glacier. Remote Sens. Environ. 186, 581-595. doi:10.1016/j.rse.2016.09.013

Laupré, G., and Skaloud, J. (2020). On the self-calibration of aerodynamic coefficients in vehicle dynamic model-based navigation. Drones 4, 32. doi:10.3390/drones 4030032

Li, X., Levin, N., Xie, J., and Li, D. (2020). Monitoring hourly night-time light by an unmanned aerial vehicle and its implications to satellite remote sensing. Remote Sens. Environ. 247, 111942. doi:10.1016/j.rse.2020.111942

Liao, Y., Mohammadi, M. E., and Wood, R. L. (2020). Deep learning classification of $2 \mathrm{D}$ orthomosaic images and $3 \mathrm{D}$ point clouds for post-event structural damage assessment. Drones 4 (2), 24. doi:10.3390/drones4020024

Liew, C. F., DeLatte, D., Takeishi, N., and Yairi, T. (2017). Recent developments in aerial robotics: a survey and prototypes overview. arXiv, 1-14. Available at: http://arxiv.org/abs/1711.10085.

Lucieer, A., Jong, S. M. d., and Turner, D. (2014). Mapping landslide displacements using structure from motion ( $\mathrm{SfM}$ ) and image correlation of multi-temporal UAV photography. Prog. Phys. Geogr. 38 (1), 97-116. doi:10.1177/ 0309133313515293

McKean, J. (2004). Objective landslide detection and surface morphology mapping using high-resolution airborne laser altimetry. Geomorphology 57 (3-4), 331-351. doi:10.1016/S0169-555X(03)00164-8
Messina, G., and Modica, G. (2020). Applications of UAV thermal imagery in precision agriculture: state of the art and future research outlook. Remote Sens. 12 (9), 1491. doi:10.3390/RS12091491

Mouginot, J., Rignot, E., Scheuchl, B., and Millan, R. (2017). Comprehensive annual ice sheet velocity mapping using Landsat-8, Sentinel-1, and RADARSAT-2 data. Remote Sens. 9 (4), 1-20. doi:10.3390/rs9040364

Nelson, E. J., Kareiva, P., Ruckelshaus, M., Arkema, K., Geller, G., Girvetz, E., et al. (2013). Climate change's impact on key ecosystem services and the human wellbeing they support in the US. Front. Ecol. Environ. 11 (9), 483-493. doi:10.1890/ 120312

Niethammer, U., James, M. R., Rothmund, S., Travelletti, J., and Joswig, M. (2012). UAV-based remote sensing of the Super-Sauze landslide: evaluation and results. Eng. Geol. 128, 2-11. doi:10.1016/j.enggeo.2011.03.012

Pering, T. D., Liu, E. J., Wood, K., Wilkes, T. C., Aiuppa, A., Tamburello, G., et al. (2020). Combined ground and aerial measurements resolve vent-specific gas fluxes from a multi-vent volcano. Nat. Commun. 11 (1), 3039. doi:10.1038/ s41467-020-16862-w

Rignot, E., and Thomas, R. H. (2002). Mass balance of polar ice sheets. Science 297 (5586), 1502-1506. doi:10.1126/science.1073888

Ruessink, B. G., Arens, S. M., Kuipers, M., and Donker, J. J. A. (2018). Coastal dune dynamics in response to excavated foredune notches. Aeolian Res. 31, 3-17. doi:10.1016/j.aeolia.2017.07.002

Scalea, J. R. (2020). Using unmanned aircraft to save lives learning to fly. JAMA Surg. 155 (4), 355-356. doi:10.1111/ajt.13770

Sigala, A., and Langhals, B. (2020). Applications of unmanned aerial systems (UAS): a delphi study projecting future UAS missions and relevant challenges. Drones 4 (1), 8. doi:10.3390/drones 4010008

Silver, R. C. (2020). Surviving the trauma of COVID-19. Science 369 (6499), 11. doi:10.1126/science.abd539

Singh, K. K., and Frazier, A. E. (2018). A meta-analysis and review of unmanned aircraft system (UAS) imagery for terrestrial applications. Int. J. Remote Sens. 39 (15-16), 5078-5098. doi:10.1080/01431161.2017.1420941

Smith, M. W., Carrivick, J. L., and Quincey, D. J. (2015). Structure from motion photogrammetry in physical geography. Prog. Phys. Geogr. 40 (2), 247-275. doi:10.1177/0309133315615805

Tan, S. (2016). Handbook of satellite applications. New York, NY: Springer, 1-21. doi:10.1007/978-1-4614-6423-5

Tatum, M. C., and Liu, J. (2017). Unmanned aircraft system applications in construction. Procedia Eng. 196, 167-175. doi:10.1016/j.proeng.2017.07.187

Tmušić, G., Manfreda, S., Aasen, H., James, M. R., Gonçalves, G., Ben-Dor, E., et al. (2020). Current practices in UAS-based environmental monitoring. Remote Sens. 12 (6), 1001. doi:10.3390/rs12061001

Turner, D., Lucieer, A., and de Jong, S. M. (2015). Time series analysis of landslide dynamics using an unmanned aerial vehicle (UAV). Remote Sens. 7 (2), 1736-1757. doi:10.3390/rs70201736

Wada, Y., Wisser, D., and Bierkens, M. F. P. (2014). Global modeling of withdrawal, allocation and consumptive use of surface water and groundwater resources. Earth Syst. Dynam. 5 (1), 15-40. doi:10.5194/esd-5-15-2014

Wallace, L., Lucieer, A., Malenovskỳ, Z., Turner, D., and Vopěnka, P. (2016). Assessment of forest structure using two UAV techniques: a comparison of airborne laser scanning and structure from motion (SfM) point clouds. Forests 7 (3), 1-16. doi:10.3390/f7030062

Wallace, L., Watson, C., and Lucieer, A. (2014). Detecting pruning of individual stems using airborne laser scanning data captured from an unmanned aerial vehicle. Int. J. Appl. Earth Obs. Geoinf. 30 (1), 76-85. doi:10.1016/j.jag.2014.01. 010

Watson, L., Straatsma, M. W., Wanders, N., Verstegen, J. A., de Jong, S. M., and Karssenberg, D. (2020). Global ecosystem service values in climate class transitions. Environ. Res. Lett. 15 (2). doi:10.1088/1748-9326/ab5aab

Wulder,M.A., Coops, N.C., Roy,D.P., White, J.C., and Hermosilla, T. (2018). Land cover 2.0. Int. J. Remote Sens. 39 (12), 4254-4284. doi:10.1080/01431161.2018.1452075

Zhang, M., Chen, F., and Tian, B. (2018). An automated method for glacial lake mapping in High Mountain Asia using Landsat 8 imagery. J. Mt. Sci. 15 (1), 13-24. doi:10.1007/s11629-017-4518-5

Zhang, M., Chen, F., Tian, B., Liang, D., and Yang, A. (2020). High-frequency glacial lake mapping using time series of sentinel-1A/1B sar imagery: an assessment for the southeastern Tibetan plateau. Int. J. Environ. Res. Public Health 17 (3), 1072. doi:10.3390/ijerph17031072 
Zhu, A. X., and Scott Mackay, D. (2001). Effects of spatial detail of soil information on watershed modeling. J. Hydrol. 248 (1-4), 54-77. doi:10.1016/S00221694(01)00390-0

Zhu, Z. (2017). Change detection using landsat time series: a review of frequencies, preprocessing, algorithms, and applications. ISPRS J. Photogramm. Remote Sens. 130, 370-384. doi:10.1016/j.isprsjprs.2017.06.013

Zurqani, H. A., Post, C. J., Mikhailova, E. A., Schlautman, M. A., and Sharp, J. L. (2018). Geospatial analysis of land use change in the Savannah River Basin using Google Earth Engine. Int. J. Appl. Earth Obs. Geoinf. 69, 175-185. doi:10. 1016/j.jag.2017.12.006
Conflict of Interest: The author declares that the research was conducted in the absence of any commercial or financial relationships that could be construed as a potential conflict of interest.

Copyright $\odot 2020$ De Jong. This is an open-access article distributed under the terms of the Creative Commons Attribution License (CC BY). The use, distribution or reproduction in other forums is permitted, provided the original author(s) and the copyright owner(s) are credited and that the original publication in this journal is cited, in accordance with accepted academic practice. No use, distribution or reproduction is permitted which does not comply with these terms. 